\title{
An optimized IFN- $\gamma$ ELISpot assay for the sensitive and standardized monitoring of CMV protein-reactive effector cells of cell- mediated immunity
}

Sascha Barabas ${ }^{1}$, Theresa Spindler ${ }^{1}$, Richard Kiener ${ }^{2}$, Charlotte Tonar ${ }^{1}$, Tamara Lugner $^{1}$, Julia Batzilla ${ }^{1}$, Hanna Bendfeldt', Anne Rascle ${ }^{1}$, Benedikt Asbach², Ralf Wagner ${ }^{2}$ and Ludwig Deml ${ }^{1,2^{*}}$

\begin{abstract}
Background: In healthy individuals, Cytomegalovirus (CMV) infection is efficiently controlled by CMV-specific cellmediated immunity (CMI). Functional impairment of CMI in immunocompromized individuals however can lead to uncontrolled CMV replication and severe clinical complications. Close monitoring of CMV-specific CMI is therefore clinically relevant and might allow a reliable prognosis of CMV disease as well as assist personalized therapeutic decisions.

Methods: Objective of this work was the optimization and technical validation of an IFN- $\gamma$ ELISpot assay for a standardized, sensitive and reliable quantification of CMV-reactive effector cells. T-activated ${ }^{\circledR}$ immunodominant CMV IE-1 and pp65 proteins were used as stimulants. All basic assay parameters and reagents were tested and optimized to establish a user-friendly protocol and maximize the signal-to-noise ratio of the ELISpot assay.

Results: Optimized and standardized ELISpot revealed low intra-assay, inter-assay and inter-operator variability (coefficient of variation CV below 22\%) and CV inter-site was lower than 40\%. Good assay linearity was obtained between $6 \times 10^{4}$ and $2 \times 10^{5}$ PBMC per well upon stimulation with T-activated ${ }^{\oplus} \mathrm{IE}-1\left(R^{2}=0.97\right)$ and pp65 $\left(R^{2}=0.99\right)$ antigens. Remarkably, stimulation of peripheral blood mononuclear cells (PBMC) with T-activated ${ }^{\circledR} \mathrm{IE}-1$ and pp65 proteins resulted in the activation of a broad range of CMV-reactive effector cells, including $\mathrm{CD}^{+} \mathrm{CD}^{+}$(Th), $\mathrm{CD}^{+} \mathrm{CD}^{+}(\mathrm{CTL}), \mathrm{CD}^{-} \mathrm{CD}^{-} 6^{+}$ (NK) and $\mathrm{CD}^{+} \mathrm{CD}^{+} 6^{+}$(NKT-like) cells. Accordingly, the optimized IFN-y ELISpot assay revealed very high sensitivity (97\%) in a cohort of 45 healthy donors, of which 32 were CMV IgG-seropositive.

Conclusion: The combined use of T-activated ${ }^{\oplus}$ IE-1 and pp65 proteins for the stimulation of PBMC with the optimized IFN-y ELISpot assay represents a highly standardized, valuable tool to monitor the functionality of CMV-specific CMI with great sensitivity and reliability.
\end{abstract}

Keywords: Cytomegalovirus, CMV, IE-1, pp65, Cell-mediated immunity, ELISpot, CD4 ${ }^{+}$, CD8$^{+}$, T helper (Th), Cytotoxic T lymphocyte (CTL), Natural killer (NK), NKT-like

\footnotetext{
* Correspondence: Ludwig.Deml@lophius.com

${ }^{1}$ Lophius Biosciences GmbH, Am BioPark 13, 93053 Regensburg, Germany

${ }^{2}$ Institute of Medical Microbiology and Hygiene, University Regensburg,

Franz-Josef-Strauss-Allee 11, 93053 Regensburg, Germany
} 


\section{Background}

Human cytomegalovirus (CMV) is endemic in all human populations, with a seroprevalence ranging from 36 to $100 \%$ depending on age, gender and location [1]. In healthy individuals, CMV replication is efficiently controlled by cell-mediated immunity (CMI). In immunocompromized individuals however, the reduced frequency and functionality of CMV-reactive effector cells is associated with severe clinical complications due to uncontrolled virus replication [1-3]. Quantitative assessment of functional CMV-reactive effector cells in immunocompromized individuals might help to identify patients at increased risk for CMV-mediated clinical complications and to adjust antiviral and immunosuppressive therapy $[3,4]$.

Reliable monitoring of CMV-specific CMI in immunocompromized individuals, such as solid-organ or allogeneic stem cell transplant recipients, requires a specific, standardized but also highly sensitive assay capable of detecting low numbers of CMV-reactive cells. Such sensitivity might be achieved by using highly immunogenic stimulants and via the reactivation of a broad spectrum of physiological effector cells involved in the protection against CMV replication in vivo, notably $\mathrm{CD}^{+}$( $\mathrm{T}$ helper or $\mathrm{Th}$ ), $\mathrm{CD}^{+}$ (cytotoxic $\mathrm{T}$ lymphocytes or $\mathrm{CTL}$ ), but also natural killer (NK) and natural killer T (NKT) cells [5-12].

Current diagnostic methods to detect and monitor CMV-specific CMI are mostly based on the restimulation of $\mathrm{CD}^{+}$and/or $\mathrm{CD}^{+}$effector cells with pools of overlapping peptides, cocktails of preselected immunodominant CMV-peptides or lysates of CMV-infected cells and the subsequent measurement of induced cytokine production (e.g. IFN- $\gamma$ ) or cell proliferation, by flow cytometry, enzyme-linked immunosorbent assay (ELISA) or enzyme-linked immunospot assay (ELISpot). A different approach consists in the direct staining with CMV-peptide-loaded multimers and enumeration of CMV-specific $\mathrm{CD}^{+} \mathrm{T}$ cells by flow cytometry. However, this method is lacking a functional readout and is restricted to certain HLA types, impeding its use in routine diagnostics.

ELISA-based assays, such as QuantiFERON ${ }^{\circ}-\mathrm{CMV}$ are advantageous in that they require low blood volumes and are easy to perform [13]. However, they are restricted to the detection of IFN- $\gamma$-producing $\mathrm{CD}^{+} \mathrm{T}$ cells and do not allow single-cell-level measurement. Due to analyte dilution, ELISA-based assays usually result in reduced sensitivity [14, 15] and often yield indeterminate results, especially in immunocompromized patients [16-21]. Intracellular cytokine staining (ICS) and subsequent flow cytometric analysis is usually more sensitive than ELISA $[15,20]$ and allows the assessment of both the functionality and the phenotype of CMV-reactivated cytokine-producing cells. However, this method is difficult to standardize and only detects the intracellular analyte, not the biologically active cytokine secreted over the stimulation period.

ELISpot-based assays identify and enumerate biologically active, cytokine-secreting cells from isolated peripheral blood mononuclear cells (PBMC), at the single-cell level both qualitatively and quantitatively [22]. ELISpot represents the most sensitive read-out system and thus is most appropriate for the detection of low-level responses [23, 24]. In particular, ELISpot is more sensitive than ICS for the detection of antigen-specific cells, such as in vitro-reactivated memory $\mathrm{T}$ cells, which produce only low amounts of cytokines [15, 25]. ELISpot was recently successfully employed over ELISA in the detection of congenital CMV infection [26-28].

Conventional CMV-specific ELISpot assays are based on the detection of IFN- $\gamma$-producing $\mathrm{CD}_{4}^{+}$and/or $\mathrm{CD}^{+}$ $\mathrm{T}$ cells, depending on the antigens used for PBMC stimulation [23, 24, 29, 30]. The careful selection and formulation of antigens is crucial to ensure specificity, sensitivity and thus a diagnostic value to the assay. We have previously shown that urea-formulated recombinant $\left(\mathrm{T}\right.$-activated $\left.{ }^{\oplus}\right)$ proteins are processed by the exogenous and endogenous antigen processing machinery, resulting in the presentation of naturally generated peptides by MHC class II and class I molecules [31]. Stimulation of $\mathrm{PBMC}$ by $\mathrm{T}_{\text {-activated }}{ }^{\otimes}$ proteins thus mimics more closely a natural infection, resulting not only in the specific activation of memory $\mathrm{T}\left(\mathrm{CD} 4^{+}\right.$, $\mathrm{CD}^{+}$) and NK cells, but also possibly in the bystander activation of NK and NKT-like cells present in the PBMC population $[31,32]$.

We describe here the establishment, optimization and standardization of a highly sensitive ELISpot assay that takes advantage of both the IFN- $\gamma$ ELISpot readout and the immunodominant and highly immunogenic $\mathrm{T}$ activated $^{\ominus}$ IE-1 and pp65 CMV proteins as stimulants. We also compared the performance of the optimized assay to that of intracellular staining and flow cytometry in healthy CMV-seropositive donors, and demonstrated the ability of T-activated ${ }^{\circledR}$ IE- 1 and pp65 antigens to activate a broad spectrum of CMV-reactive cells, including $\mathrm{CD}^{+} \mathrm{CD}^{+}$(Th), $\mathrm{CD}^{+} \mathrm{CD}^{+}$(CTL), $\mathrm{CD}^{-} \mathrm{CD}^{+} 6^{+}$(NK) and $\mathrm{CD}^{+} \mathrm{CD}^{+} 6^{+}$(NKT-like) cells. Therefore, the com-

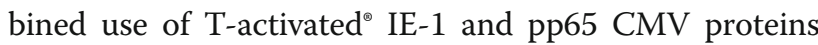
with our optimized IFN- $\gamma$ ELISpot defines a highly sensitive assay meeting all conditions for a reliable and standardized immune monitoring diagnostic tool.

\section{Methods}

Proteins, ELISpot plate precoating and detection conjugate Urea-formulated $\mathrm{T}$-activated ${ }^{\oplus}$ proteins were prepared as previously described [31]. The $\mathrm{T}^{\text {-activated }}{ }^{\odot}$ immunodo- $^{-}$ minant region of CMV pp65 (amino acids 366 to 546, 
hCMV strain AD169 [33]) was provided by MIKROGEN (MIKROGEN GmbH, Neuried, Germany). Full length IE-1 (hCMV towne strain) was kindly provided by Christina Paulus and Michael Nevels (University of Regensburg, Germany). T-activation ${ }^{\bullet}$ of IE-1 was performed by Lophius Biosciences. Staphylococcal enterotoxin B (SEB; 11249738001, Roche Diagnostics GmbH, Mannheim, Germany) and phytohemagglutinin (PHA; S4881, Sigma-Aldrich Chemie GmbH, Munich, Germany) were used as positive controls for PBMC stimulation. 96well ELISpot plates (MAIPS4510, Merck Millipore, Merck KGaA, Darmstadt, Germany) and 8-well ELISpot strips (M8IPS4510, Merck Millipore) each pre-coated with antihuman-IFN- $\gamma$ mAb 1-D1K (MabTech, Nacka Strand, Sweden) as well as the detection conjugate mAb-AP (7-B6-1) (MabTech, Nacka Strand, Sweden) coupled with alkaline phosphatase (Roche, Basel, Switzerland) were obtained from Microcoat Biotechnologie $\mathrm{GmbH}$.

\section{Blood collection and PBMC preparation}

Blood samples were collected in lithium heparin tubes (S-Monovette ${ }^{\circ}$ Sarstedt, SARSTEDT AG \& Co., Nümbrecht, Germany) from healthy individuals with known CMV serostatus by venipuncture and stored for up to 8 hours at room temperature $\left(18-25^{\circ} \mathrm{C}\right)$ until further processing. Isolation of peripheral blood mononuclear cells (PBMC) was performed using standard Ficoll-Paque density centrifugation as specified by the manufacturer (Pancoll human, PAN-Biotech GmbH, Aidenbach, Germany). PBMC were finally suspended in serum-free $A I M-V^{\diamond}$ medium (Life Technologies, Inc., Grand Island, NY) and counted either manually in a Neubauer's chamber or using the Hem-o-test 2000 cellcounting device (BGT BioGenTechnologies $\mathrm{GmbH}$, Steinfurt, Germany). Automated cell counting was performed in the whole blood venous mode of the calibrated analyzer.

\section{ELISpot assay}

IFN- $\gamma$ ELISpot assays were performed as previously described [31] unless specified otherwise in the Results section. Briefly, $2 \times 10^{5}$ freshly isolated PBMC were plated in four replicates into 96-well ELISpot plates or 8-well ELISpot strips precoated with anti-human-IFN- $\gamma$ $\mathrm{mAb}$ 1-D1K (Microcoat Biotechnologie $\mathrm{GmbH}$ ) and stimulated for $19 \mathrm{~h}$ at $37{ }^{\circ} \mathrm{C}$ under $5 \% \mathrm{CO}_{2}$ with either $3 \mu \mathrm{g} / \mathrm{ml} \mathrm{T}$-activated ${ }^{\circ}$ pp65 antigen or $15 \mu \mathrm{g} / \mathrm{ml} \mathrm{T}$-activated $^{\bullet}$ IE-1 protein. As unstimulated control (neg.), cells were incubated for $19 \mathrm{~h}$ in cell culture medium. After cell removal, plates were developed for $2 \mathrm{~h}$ at room temperature $\left(18-25^{\circ} \mathrm{C}\right)$ in the presence of $0.4 \mathrm{U} / \mathrm{ml} \mathrm{IFN-}$ $\gamma$-specific alkaline phosphatase-coupled mAb 7-B6-1. Spot detection was performed following incubation for $6 \mathrm{~min}$ in the dark with a 1-step nitroblue tetrazolium-5-bromo-4-chloro-3-indolylphosphate substrate (Thermo Fischer Scientific, Waltham, USA). IFN- $\gamma$ specific spot-forming cells (SFC) were counted using a Bioreader 5000 E $\alpha$ (BIO-SYS GmbH, Karben, Germany). Of note, comparable results were obtained on two other readers (AID Elispot Robotic System ELROB05i and CTL ImmunoSpot ${ }^{\circ}$ S6).

\section{Intracellular cytokine staining}

Intracellular cytokine staining was performed as previously described [31], with the following modifications. PBMC from six healthy CMV-seropositive donors were isolated and four replicates each were stimulated for $6 \mathrm{~h}$ at $37{ }^{\circ} \mathrm{C}$ and $5 \% \mathrm{CO}_{2}$ with $3 \mu \mathrm{g} / \mathrm{ml} \mathrm{T}$-activated ${ }^{\circ}$ pp65 antigen or with $15 \mu \mathrm{g} / \mathrm{ml} \mathrm{T}$-activated ${ }^{\circ} \mathrm{IE}-1$ protein in the presence of co-stimulatory anti-CD28 and anti-CD49d monoclonal antibodies (BD, Heidelberg, Germany). The unstimulated PBMC control cells were incubated with co-stimulatory anti-CD28 and anti-CD49d molecules only. Stimulation with SEB and anti-CD28 + anti-CD49d served as positive control. After the first two hours of incubation, $1 \mu \mathrm{g} / \mathrm{ml}$ brefeldin A (BFA, Sigma-Aldrich Chemie $\mathrm{GmbH}$, Steinheim, Germany) was added to prevent cytokine secretion from activated cells. Surface markers (CD3, CD4, CD8, CD56) were stained for $30 \mathrm{~min}$ at $4{ }^{\circ} \mathrm{C}$ using the following conjugated antibodies (all from Biolegend, London, UK): anti-CD3 APC-Cy7, anti-CD4 Brilliant Violet 421, anti-CD8 FITC, antiCD56 PerCP. Cells were fixed and permeabilized for $30 \mathrm{~min}$ at $4{ }^{\circ} \mathrm{C}$ in BD Cytofix/Cytoperm (BD, Heidelberg, Germany). Intracellular staining of IFN- $\gamma$ was performed using anti-IFN- $\gamma$ APC (Biolegend, London, UK) in BD Perm/Wash Buffer (BD, Heidelberg, Germany) for $45 \mathrm{~min}$ at $4{ }^{\circ} \mathrm{C}$. Samples were analyzed on a BD FACSCanto $^{\text {Tx }}$ II flow cytometer (Becton Dickinson, USA). Live-gating of cells was performed during acquisition. Mean (SD) number of event acquisition was 172,904 $(108,298)$. Results were reported as percentage of the gated population producing IFN- $\gamma$ (dot plots) and as the number of IFN- $\gamma^{+}$cells/200,000 lymphocytes (bar graphs).

\section{Serology}

The CMV serological testing of blood donors was performed using the fully automated CMV immunoglobulin $M$ (IgM) and IgG tests on the Architect instrument (Abbott Laboratories, Abbott Park, IL) or the BEP ${ }^{\circ}$ III system (Siemens Healthcare) by the diagnostics department of the Institute for Medical Microbiology and Hygiene (University of Regensburg, Germany). CMV IgG-serology was used as primary reference measurement procedure (gold standard method). 


\section{Statistics}

Statistics applied to assay development was performed using SigmaPlot Version 11.0 and GraphPad Prism 5.04. At the start of this study, a positive ELISpot test result was defined by a statistically significant difference between quadruplicate SFC values of non-stimulated and specifically stimulated approaches of at least one of the two antigens used, calculated using the Mann-Whitney $U$-Test (MWU) (SigmaPlot). Two-sided exact $P$ values are reported. $P$ values $<0.05$ were considered statistically significant. Statistical analyses to assess variations between two or more settings were performed by generating arithmetic means for all replicates of each given setting. Those means were grouped to generate an overall arithmetic mean and standard deviation. The coefficient of variation in \% (ratio of the standard deviation to the mean multiplied by 100) was calculated in Microsoft Excel. The curve fitting for sigmoidal curves of the titration experiment (Fig. 1) was performed using the four parameter logistic function of GraphPad Prism 5.04. For the assessment of the ELISpot assay sensitivity in seropositive healthy blood donor collectives, the nonparametric Mann-Whitney $U$-Test (MWU test) was performed to determine if a significant difference exists between the groups of negative control and stimulation quadruplicates. Multiple-group comparisons were performed using a non-parametric One-way ANOVA (Kruskal-Wallis test) with Dunn's multiple comparison post test. SFC values were depicted using GraphPad Prism 5.04 either as Tukey box plots showing median values (horizontal line), interquartile ranges (IQR: Q3-Q1), lower and upper whiskers (Q1-1.5xIQR and Q3 + 1.5xIQR

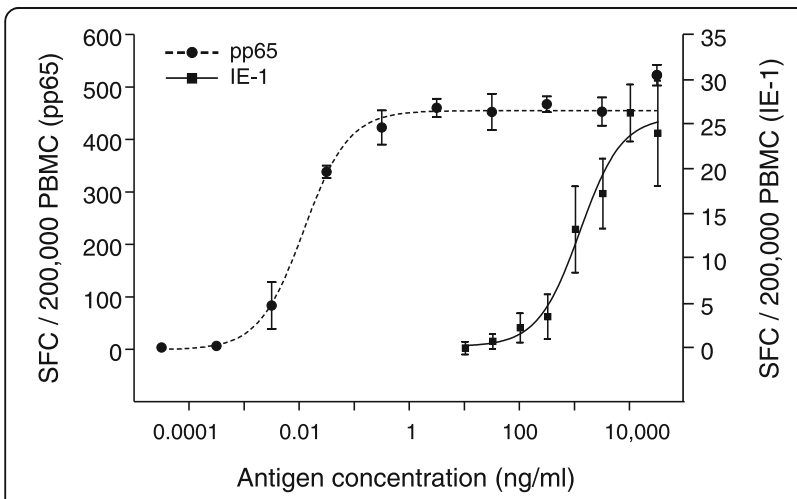

Fig. 1 Determination of optimal concentrations of T-activated ${ }^{\circledR}$ pp65 and IE-1 for the stimulation of PBMC. PBMC were isolated from one CMV-seropositive healthy donor blood sample and stimulated for $19 \mathrm{~h}$ with increasing concentrations of T-activated ${ }^{\circledR}$ pp65 $(31.6 \mathrm{fg} / \mathrm{ml}-31.6 \mu \mathrm{g} /$ $\mathrm{ml}$; black circles) or IE-1 (0.01-31.6 $\mu \mathrm{g} / \mathrm{ml}$; black squares). IFN- $\gamma$ ELISpot results of four replicates are expressed as mean SFC/200,000 PBMC. Error bars represent standard deviations. The $Y$-axis scale was adjusted to pp65- (left) and IE-1- (right) specific values to optimize data resolution. Curve fitting was made using the four parameter logistic function of GraphPad Prism 5.04 respectively) and outliers (below Q1-1.5xIQR and above $\mathrm{Q} 3+1.5 \mathrm{xIQR}$; black dots), or as histograms. For assay validation of optimized ELISpot, positivity cut-off was calculated on IFN- $\gamma$ ELISpot results obtained from a collective of 45 healthy donors using SAS 9.2 Software and VFP (Variance Function Program; option "Simple variance function estimate") version 12.0.

\section{Results}

\section{IFN- $\gamma$ ELISpot assay optimization following PBMC} stimulation with T-activated $^{\circledR}$ IE-1 and pp65 CMV antigens Freshly isolated PBMC were used for the ELISpot assay. To prevent loss in $\mathrm{T}$ cell functionality, for instance due to activated granulocytes [34], heparinized blood samples were processed with no further additives within $8 \mathrm{~h}$. A total number of $2 \times 10^{5}$ PBMC per well was chosen for the development of the ELISpot assay protocol as this cell count is below confluency and can usually be obtained from samples of less than $15 \mathrm{ml}$ whole blood. The CMV immediate-early protein IE- 1 and the late tegument protein pp65 represent well-characterized immunodominant T cell antigens [1, 24, 35]. Full-length IE-1 and a 181 amino-acid C-terminal fragment of pp65 were produced and formulated in the presence of urea $\left(\right.$ T-activation $\left.{ }^{\odot}\right)$ to increase their stimulatory capacity for different types of CMV-reactive effector cells of cellmediated immunity [31]. Optimal T-activated ${ }^{\odot}$ antigen concentration was first determined by performing doseresponse experiments. Freshly isolated PBMC of one healthy CMV-seropositive donor were stimulated with $31.6 \mathrm{fg} / \mathrm{ml}$ to $31.6 \mu \mathrm{g} / \mathrm{ml}$ T-activated ${ }^{\circledR}$ pp65 or with 0.01 to $31.6 \mu \mathrm{g} / \mathrm{ml}$ T-activated ${ }^{\oplus}$ IE-1, and the number of IFN$\gamma$ secreting cells was determined by IFN- $\gamma$ ELISpot. T-activated ${ }^{\oplus}$ pp65 revealed a much stronger capacity to stimulate IFN- $\gamma$ secreting effector cells than T-activated ${ }^{\circ}$ IE-1, reaching a plateau of responsiveness between 0.316 and $3.16 \mathrm{ng} / \mathrm{ml}$ pp65 vs. approximately $31.6 \mu \mathrm{g} /$ $\mathrm{ml}$ for IE-1 (Fig. 1). Accordingly, T-activated ${ }^{\circledR}$ antigen concentrations of $3 \mu \mathrm{g} / \mathrm{ml}$ pp65 and $15 \mu \mathrm{g} / \mathrm{ml} \mathrm{IE-1}$ were selected for further PBMC stimulations and ELISpot assays.

Assay sensitivity and specificity were determined by stimulating PBMC isolated from 10 each CMVseropositive and CMV-seronegative healthy donors with the defined pp65 and IE-1 T-activated ${ }^{\circledR}$ antigen concentrations. The number of reactive effector cells was quantified by IFN- $\gamma$ ELISpot. Significant stimulation was defined using a Mann-Whitney $U$-Test as a statistically significant difference between SFC values of nonstimulated and CMV antigen-stimulated conditions (each in quadruplicate). T-activated ${ }^{\circledR}$ pp65 and IE-1 induced a significant activation of responsive effector cells in 10 out of 10 and 9 out of 10 PBMC preparations from individual CMV-seropositive donors, respectively (Fig. 2). 

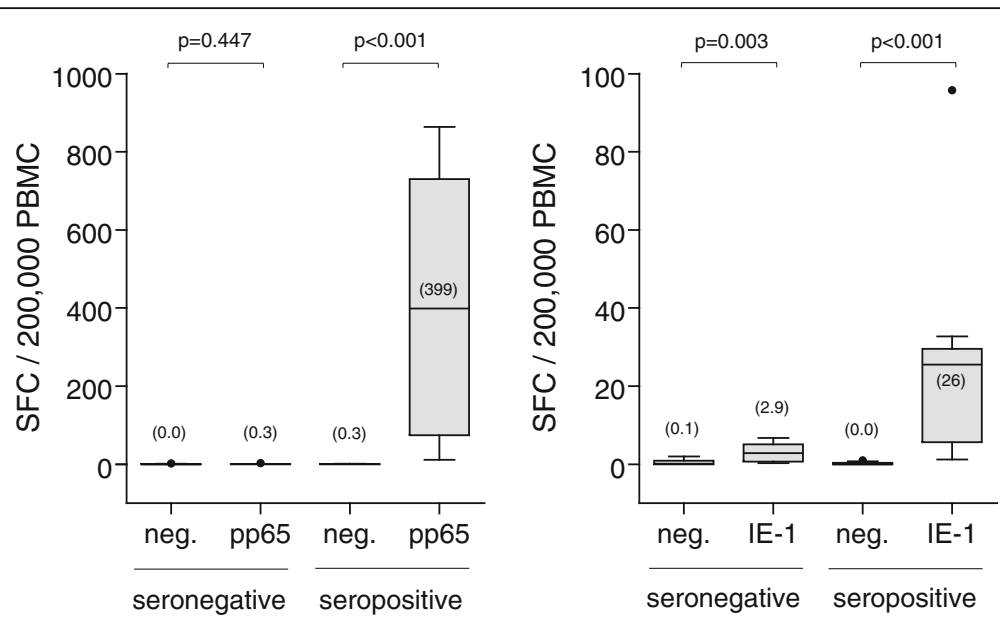

Fig. 2 Determination of assay sensitivity and specificity. PBMC from 10 each CMV-seropositive and CMV-negative healthy blood donors were left unstimulated (neg.) or were stimulated with T-activated ${ }^{\circledR}$ pp65 or IE-1 and IFN- $\gamma$ ELISpot assays were conducted as before. Mean SFC values per 200,000 PBMC of 4 replicates are shown as box plots. Median values (horizontal black lines) are indicated in brackets. Y-axis scales were adjusted in each graph for better resolution of SFC counts. Median age and range of CMV-seronegative and CMV-seropositive subjects was 28 (24-53) and 31 (23-56) years. Gender distribution in CMV-seronegative (30\% male and 70\% female) and CMV-seropositive (25\% male and 75\% female) groups was comparable. Differences between unstimulated and stimulated conditions were tested using the non-parametric two-sided Mann-Whitney $U$ (MWU) test. P-values $<0.05$ were considered statistically significant

In this collective, T-activated ${ }^{\ominus}$ pp65 showed an overall greater capacity to activate responsive cells with a median of 399 SFC/200,000 PBMC (range 12-864 SFC/ 200,000 PBMC), compared to T-activated ${ }^{\oplus}$ IE-1 with a median of $26 \mathrm{SFC} / 200,000 \mathrm{PBMC}$ (range 1.3-96 SFC/ 200,000 PBMC). Nevertheless, substantial response of up to 96 SFC/200,000 PBMC was detected in response to T-activated ${ }^{\oplus}$ IE-1 in individual samples of CMVseropositive donors (Fig. 2). All 10 PBMC samples (100\%) from different CMV-seronegative donors showed negative test results after stimulation with pp65 (median 0.3 SFC/200,000 PBMC; range 0-2.8), while 9 out of 10 (90\%) PBMC samples from CMV-seronegative individuals were negative after stimulation with IE-1 (median 2.9 SFC/200,000 PBMC; range 0.3-6.8). Spot count within CMV-seronegative IE-1-stimulated PBMC was higher than in $\mathrm{CMV}$-seronegative pp65-stimulated PBMC but did not exceed 7 SFC/200,000 PBMC (Fig. 2).

IFN- $\gamma$ has been shown to be secreted continuously during antigen stimulation. Thus, signal intensity in IFN- $\gamma$ ELISpot is dependent on the duration of stimulation $[14,36]$. The duration of antigen stimulation in IFN- $\gamma$ ELISpot reported in the literature usually ranges from 16 to $24 \mathrm{~h}$ [37-42]. To address the influence of the incubation time on the test results, IFN- $\gamma$ ELISpot were performed on PBMC from 3 independent CMVseropositive healthy donors following stimulation with T-activated ${ }^{\oplus}$ pp65 and IE-1 antigens for 17, 19 and $21 \mathrm{~h}$. No statistically significant differences in SFC numbers were detected between the 3 conditions (Fig. 3), demonstrating signal stability in this time range. Thus, an incubation time of $19 \mathrm{~h}$ was chosen for the optimized ELISpot assay.

Numerous protocol variables can affect ELISpot test results. For instance, the medium used for primary cell culture often includes serum which contains various batch-dependent non-characterized bioactive molecules in different concentrations [43]. In order to define standardized cell culture conditions, the impact on the assay performance of different serum-containing media (RPMI 1640 supplemented with $5 \%$ of either FCS, human AB, synthetic NTA or synthetic NTS) and of serum-free media (AIM-V ${ }^{\oplus}$, UltraCulture) was investigated. Serumfree media yielded the best effector cell responses, comparable to that of RPMI 1640 supplemented with 5\% FCS (Fig. 4a). In addition, AIM-V ${ }^{\bullet}$ exhibited lowest background signals in unstimulated conditions (Fig. 4b), thus maximizing signal-to-noise ratio. Consequently, the ELISpot protocol was further established using AIM-V ${ }^{\circ}$ serum-free medium.

ELISpot assays can be performed with various membrane materials, including nitrocellulose (NC), mixed cellulose ester (MCE) and polyvinylidene fluoride (PVDF). We compared IFN- $\gamma$ ELISpot results from PBMC samples of six healthy individuals (four replicates each, two preparations per donor) employing the most commonly used MCE plates, PVDF plates and PVDF strips from Millipore (Merck Millipore, Merck KGaA, Darmstadt, Germany). PVDF membranes require an activation step with ethanol prior to binding of the capture antibody. In addition, more stringent washing steps prior to spot development were needed using PVDF-based 


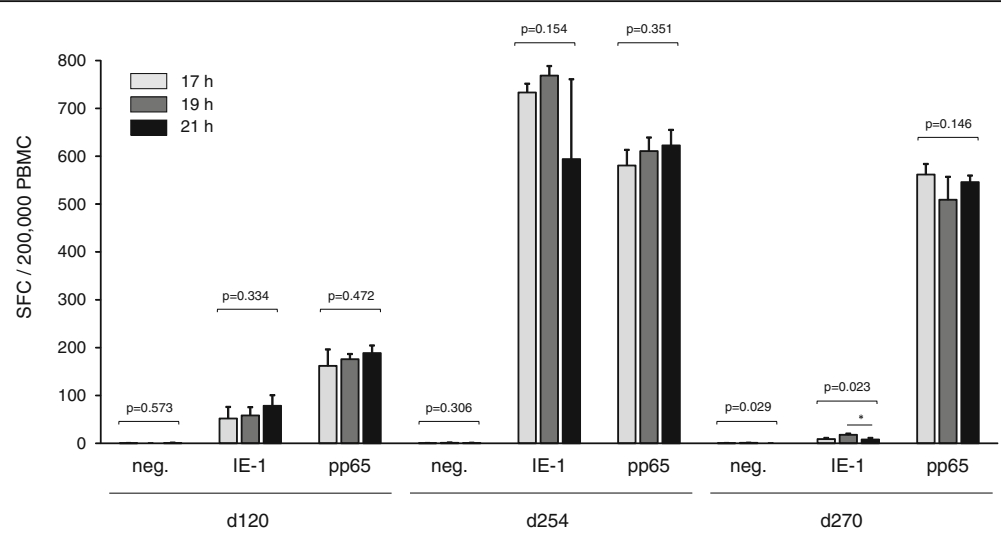

Fig. 3 Effect of duration of antigen stimulation on IFN- $\gamma$ ELISpot test results. SFC counts (means of four replicates) in IFN- $\gamma$ ELISpot following stimulation of PBMC samples from three CMV-seropositive healthy donors (d120, 32-year-old male; d254, 62-year-old female; d270, 22-year-old female) with T-activated ${ }^{\Phi}$ IE-1 or pp65 for 17, 19 and 21 h. Unstimulated PBMC (neg.) were used as a negative control. Differences between stimulation durations were tested using the non-parametric two-sided One-way ANOVA Kruskal-Wallis test $(* P<0.05)$. P-values $<0.05$ were considered statistically significant

plates compared to MCE plates, to avoid undesirable background staining of membranes. Nevertheless, the resolution of the detected spots in terms of sharpness and homogeneity was improved on PVDF membranes (not shown), resulting in higher spot counts compared to MCE membranes (up to 10-times more in the case of IE-1 stimulations, with a median SFC of 155 vs. 13/ 200,000 PBMC, respectively; Fig. 5). Since PVDF 8-well strips were more performant and because their use might allow reduced costs, in particular when single patient samples are tested in clinical routine, the PVDF 8 -well-strip format was chosen for the optimized assay development.

Optimal coating of microtiter plates with capture antibody is crucial for a robust assay performance. The density of IFN- $\gamma$ capture antibody bound to the PVDF membrane should not be limiting and, in particular, should allow the reliable detection of high spot counts. PVDF strips were coated with increasing concentrations (2.5 to $7.5 \mu \mathrm{g} / \mathrm{ml}$ ) of anti-IFN- $\gamma$ antibody. PBMC from five CMV-seropositive donors were seeded into the coated wells and either left unstimulated or stimulated with T-activated ${ }^{\circ}$ IE-1 or pp65. In the range of 2.5 to $7.5 \mu \mathrm{g} / \mathrm{ml}$, increasing antibody concentrations had no effect on background staining in unstimulated PBMC (median SFC of 0 to $0.5 / 200,000$ PBMC regardless of IFN- $\gamma$ capture antibody concentration; Figs. $6 a-b)$. Similarly, IE-1-specific low-to-moderate SFC levels (medians of 19 to $26 \mathrm{SFC} / 200,000 \mathrm{PBMC}$ ) were comparable in all coating-antibody conditions (Fig. 6a). The same was true for pp65-specific responses up to $\sim 300 \mathrm{SFC} /$ 200,000 PBMC (donors d032, d120 and d241; Fig. 6c).
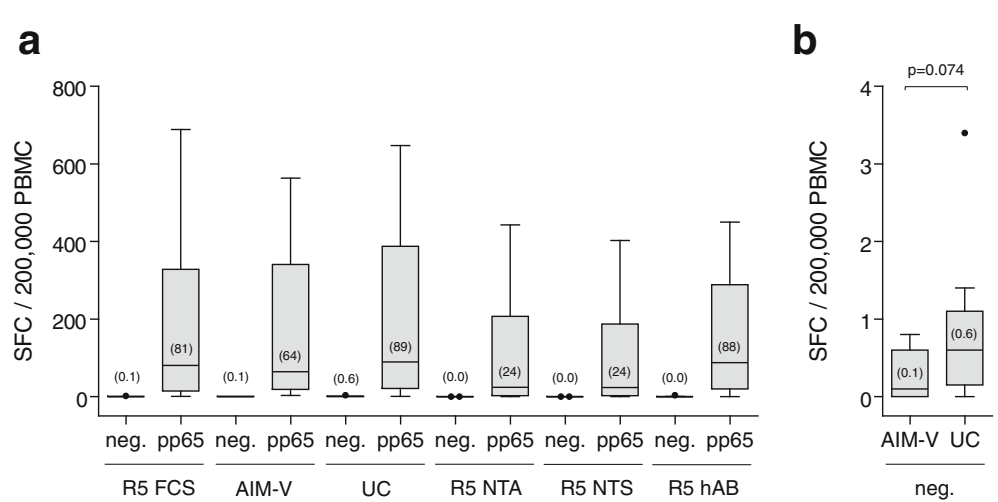

Fig. 4 Evaluation of different cell culture media on the performance of IFN- $\mathrm{E}$ ELISpot. a Boxplot diagram showing ELISpot results upon stimulation of PBMC of 10 CMV-seropositive healthy blood donors (median age and range of 31 (26-54) years; $40 \%$ male and $60 \%$ female) with T-activated ${ }^{\circledR}$ pp65 in various cell culture media. Median values (horizontal black lines) are indicated in brackets. Differences between medium conditions among stimulated conditions were tested using the non-parametric two-sided One-way ANOVA Kruskal-Wallis test ( $p=0.613)$. $\mathbf{b}$ ELISpot results of the nonstimulated cells incubated in AIM-V or in UltraCulture (UC) serum-free media are shown separately with an expanded Y-axis scale. Differences between both conditions were tested using the non-parametric two-sided MWU test $(p=0.074)$. P-values $<0.05$ were considered statistically significant. Serum-containing media were composed of RPMl 1640 supplemented with 5\% serum (R5): FCS, NTA, NTS or human AB (hAB) 


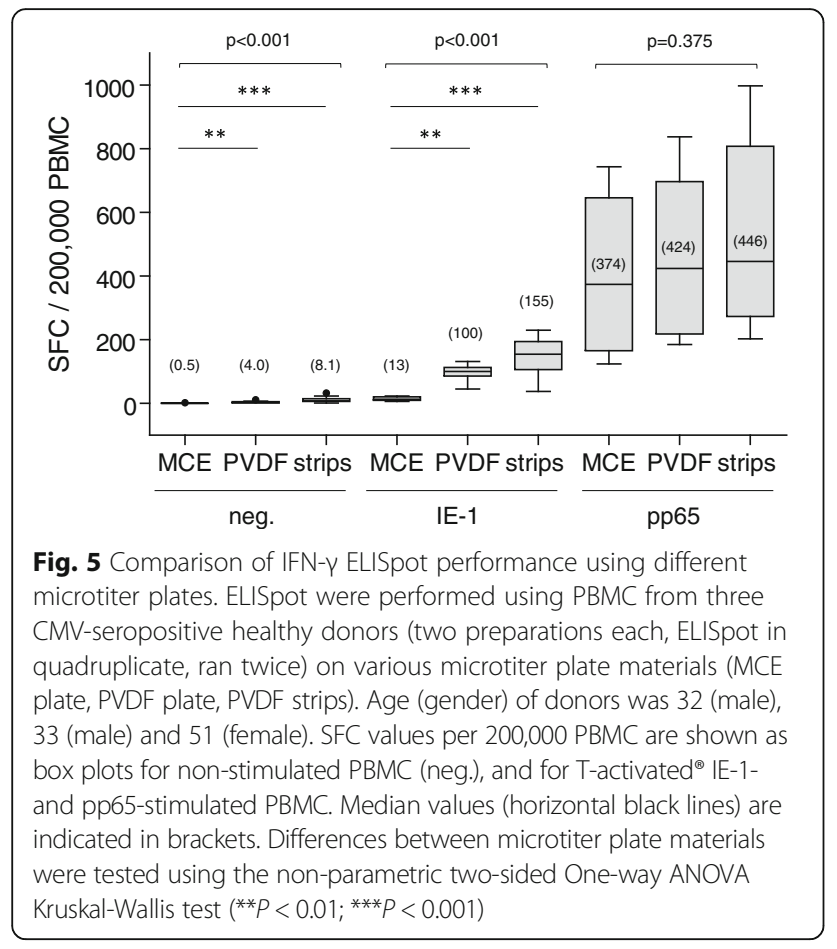

In contrast, in individual donors with higher spot counts (e.g., d172, d202; Fig. 6c), detection of pp65reactive cells increased in a dose-dependent manner with the concentration of IFN- $\gamma$ capture antibody used for coating, especially between 2.5 and $5 \mu \mathrm{g} / \mathrm{ml}$ antibody. At antibody concentrations of $5 \mu \mathrm{g} / \mathrm{ml}$ and beyond, spot counts remained stable (Figs. 6b-c). Based on these results, a concentration of $5 \mu \mathrm{g} / \mathrm{ml}$ IFN- $\gamma$ capture antibody was chosen for coating in the optimized ELISpot protocol.

ELISpot assays rely on the detection of captured cytokine by cytokine-specific antibodies, which can be either directly coupled to a reporter enzyme (one-step assay development), like alkaline phosphatase (AP), or a combination of a biotinylated secondary antibody and a streptavidin-conjugated reporter enzyme (two-step assay development). A one-step assay development saves handling time and prevents operator errors. APconjugated mAb (7-B6-1) (MicroCoat Biotechnologie $\mathrm{GmbH}$, Bernried, Germany) was used as detection conjugate for the standardized ELISpot protocol. Different incubation parameters (e.g., $0.5-3 \mathrm{~h}$ at $37^{\circ} \mathrm{C}, 2 \mathrm{~h}$ at room temperature $\left[\mathrm{RT}, 18-25{ }^{\circ} \mathrm{C}\right]$ ) were tested. Spot counts were comparable in all conditions. However, spot

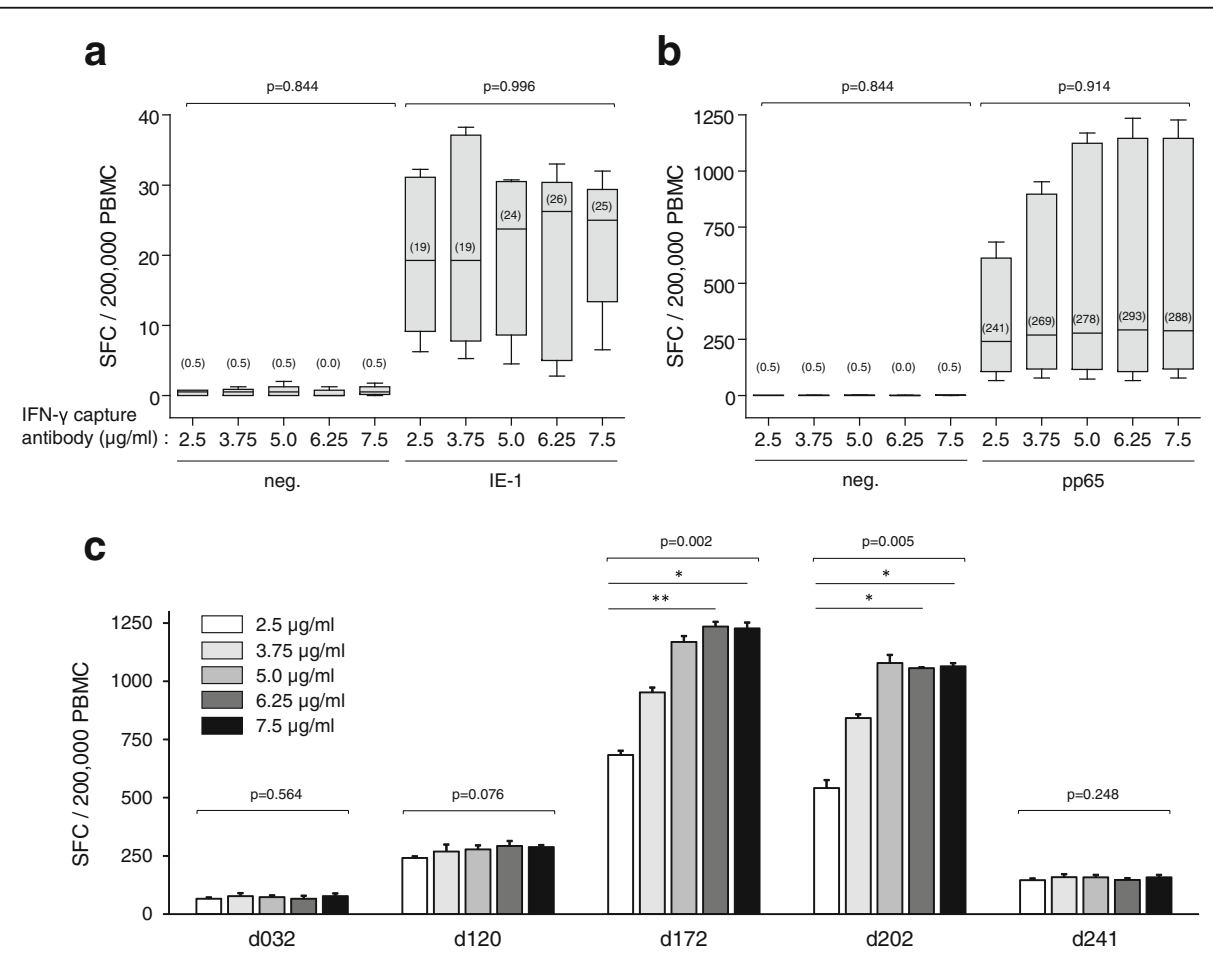

Fig. 6 titration of the ifn- $\gamma$ capture antibody. PBMC (four replicates each) from five CMV-seropositive healthy donors (median age and range of 31 (22-49) years; 1 male and 4 female) were seeded on PVDF microtiter strips coated with increasing concentrations (2.5 to $7.5 \mu \mathrm{g} / \mathrm{ml})$ of IFN- $\gamma$ capture antibody. Cells were left unstimulated (neg.) (a, b) or were stimulated with T-activated ${ }^{\oplus} \mathrm{IE}-1(\mathbf{a})$ or pp65 (b, c) CMV antigens, as before. SFC mean values per 200,000 PBMC are shown as box plots for the collective of 5 donors (median values indicated in brackets) (a, b) and as histograms (c) for pp65-stimulated PBMC of individuals donors (d032, d120, d172, d202, d241). Differences between coating conditions were tested using the non-parametric two-sided One-way ANOVA Kruskal-Wallis test $\left({ }^{*} P<0.05 ;{ }^{* *} P<0.01\right)$ 
morphology and thus proper detection was best upon incubation with AP-conjugate for $2 \mathrm{~h}$ at $\mathrm{RT}$, compared to other conditions (not shown). Increase in the concentration of the detection conjugate from 0.025 to $0.4 \mathrm{U} /$ $\mathrm{ml}$ resulted in slightly elevated SFC median values for pp65, and the maximum spot counts exceeded those generated by the two-step assay development (not shown). Therefore, a one-step assay development for $2 \mathrm{~h}$ at RT with $0.4 \mathrm{U} / \mathrm{ml}$ detection conjugate was chosen.

Finally, standardization of the SFC staining reaction was addressed to complete assay optimization. Duration of incubation with the AP substrate affects spot size and/or background level, and is thus critical for reliable spot enumeration. A one-step chromogenic alkaline phosphatase substrate NBT/BCIP (Thermo Fischer Scientific, Waltham, USA) was used as staining solution, and incubation times ranging from 2 to $13 \mathrm{~min}$ in the dark were evaluated. SFC counts were comparable in all conditions. However, shorter incubation times resulted in smaller spot diameter, while longer incubation times yielded enhanced background levels (data not shown). Therefore, a staining duration of six minutes in the dark was defined for the optimized ELISpot protocol.

Linearity and precision of the optimized CMV ELISpot assay The optimized ELISpot protocol was used to determine the working range of PBMC that ensure assay linearity. PBMC from one healthy CMV-seropositive donor were seeded at a density ranging from $2 \times 10^{4}$ to $2.5 \times 10^{5}$ PBMC per well. For cell numbers between $6 \times 10^{4}$ and 2 $\times 10^{5}$ PBMC per well, ELISpot counts were directly proportional to the number of PBMC seeded, following stimulation with either IE-1 (linear regression analysis; $\left.R^{2}=0.97\right)$ or pp65 $\left(R^{2}=0.99\right) \quad$ (Fig. 7a). Because of the usually lower spot count resulting from IE-1 stimulation, the use of $2 \times 10^{5}$ PBMC per well was chosen for the standardized ELISpot assay, to ensure sufficient SFC values.

To further verify the linearity between the number of CMV-reactive effector cells and enumerated SFC, increasing numbers of PBMC from one CMV-seropositive healthy donor were seeded and the total number of PBMC was adjusted to $2 \times 10^{5}$ per well using PBMC from one CMV-seronegative donor. Two donor pairs $(\mathrm{d} 034+\mathrm{d} 219, \mathrm{~d} 204+\mathrm{d} 067)$ that showed no alloreactivity in a 19-h co-culture were chosen for these experiments. Due to low SFC numbers (below $20 \mathrm{SFC} /$ 200,000 PBMC), IE-1 stimulation results showed increased variability compared to pp65 and did not allow a reliable linearity calculation $\left(\mathrm{R}^{2}\right.$ values below 0.96 ; data not shown). ELISpot assay results following pp65 stimulation showed a good linear correlation for both donor pairs, with $\mathrm{R}^{2}$ values of $0.99(\mathrm{~d} 034+\mathrm{d} 219)$ and 0.98 $(\mathrm{d} 204+\mathrm{d} 067)$ in the linear regression analysis (Fig. 7b).

Precision and repeatability of the optimized assay were evaluated by calculating the intra-assay, inter-assay, inter-operator and inter-site variability. In each case, PBMC from three CMV-seropositive healthy donors were tested in quadruplicate, and variability was assessed by calculating the coefficient of variation $(\mathrm{CV})$, defined as the ratio of the standard deviation to the mean. CV for ELISpot values $<10$ SFC/200,000 PBMC were not calculated (see positivity cut-off calculation below). CV intra-assay reached $14 \%$ for IE-1 stimulation and $6 \%$ for pp65 stimulation (Additional File 1: Table S1). CV interassay did not exceed $17 \%$ for IE-1 and $22 \%$ for pp 65 (Additional File 1: Table S2). CV inter-operator was below $13 \%$ and $18 \%$ for IE-1 and pp65 respectively (Additional File 1: Table S3). Finally, inter-site variation, which is essential for assay validation for diagnostics
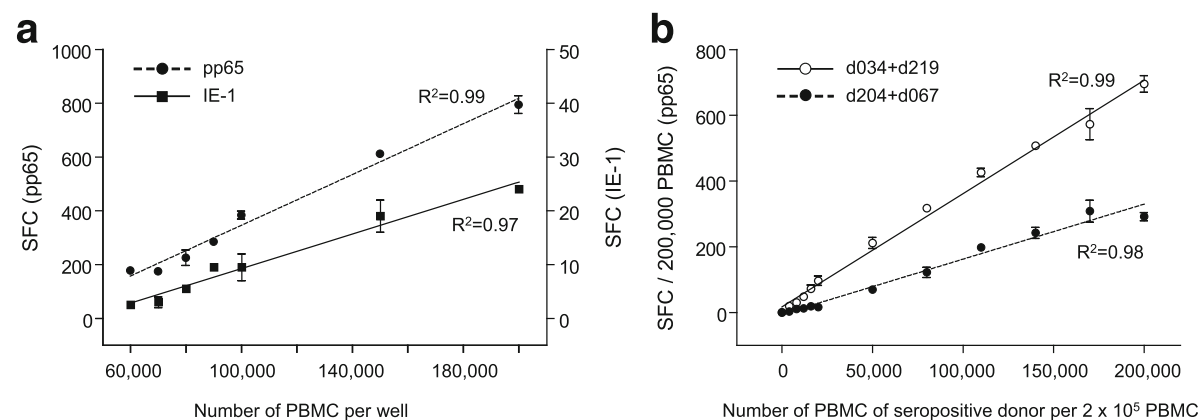

Fig. 7 IFN- $\gamma$ ELISpot assay linearity. a Working range of PBMC per ELISpot assay. Increasing number of PBMC from one CMV-seropositive healthy donor were seeded per well and ELISpot assays were performed as described, following stimulation with T-activated ${ }^{\oplus}$ IE-1 or pp65. Mean SFC values and standard deviation obtained for 60,000-200,000 PBMC per well are depicted. Scale of the Y-axes was adjusted for pp65 (left) and IE-1 (right) for a better data resolution. $\mathbf{b}$ Linearity between the number of CMV-reactive PBMC and enumerated SFC. The indicated numbers of PBMC from one CMV-seropositive healthy donor were mixed with PBMC from one CMV-seronegative donor (up to 200,000 total PBMC) and stimulated with T-activated ${ }^{\oplus}$ pp65 antigen according to the optimized protocol. Mean SFC values and standard deviation of quadruplicate measurements are shown for two donor pairs (d034 + d219, d204 + d067). In both panels, regression lines and corresponding coefficient of determination $R^{2}$ were generated using the regression line tool of GraphPad Prism 5.04 
purposes, was evaluated. Whole blood samples were simultaneously collected from three CMV-seropositive healthy donors and shipped (under constant condition at $\mathrm{RT}$ ) to four different laboratories in Germany. PBMC were freshly isolated and ELISpot assays performed according to the optimized protocol by a total of 7 operators. CV inter-site reached a maximum of 39\% for IE-1 and of 28\% for pp65 (Additional File 1: Table S4).

Evaluation of at least four independent measurements has been recommended to achieve statistically significant ELISpot results [44-46]. To address the influence of intra-replicate variations on the assay outcome, we compared ELISpot results of quintuplicate and quadruplicate measurements of each control and antigen stimulations. No significant variation of test results was found (data not shown). Therefore, quadruplicate measurements of unstimulated and T-activated ${ }^{\oplus}$ IE-1- and pp65-stimulated conditions allow assay reliability, as well as practicability in combination with the use of 8-well strips.

Staphylococcal enterotoxin B (SEB) is a powerful superantigen, and phytohemagglutinin (PHA) a potent mitogen, both inducing massive IFN- $\gamma$ secretion by $\mathrm{T}$ cells $[47,48]$. Thus SEB and PHA are suitable positive controls for cell viability, successful stimulation of cytokine secretion and overall $\mathrm{T}$ cell functionality. This is particularly important for result interpretation when low $\mathrm{T}$ cell frequency is expected, for instance in recipients of allogeneic stem cell transplantation. In the optimized ELISpot assay, stimulations of test samples with either SEB or PHA are performed in duplicate.

In addition, an effector cell-independent operator control was established to validate proper assay performance. This operator control is based on the detection of recombinant IFN- $\gamma$ upon direct incubation with the immobilized anti-human-IFN- $\gamma$ mAb (1-D1K) capture antibody. This control, also performed in duplicate, should yield a homogeneous dark staining of the PVDF membrane.

Technical assay validation: definition of a positivity cut-off To ease result interpretation of the IFN- $\gamma$ ELISpot assay and to maximize specificity (i.e. avoid false positives within unstimulated conditions and within stimulated conditions in CMV-seronegative individuals), a technical cut-off was defined. IFN- $\gamma$ ELISpot assays were performed according to the optimized protocol on PBMC from 45 healthy donors, of which 32 were CMV IgG-seropositive (Table 1).

Median and range of SFC values from unstimulated PBMC of CMV-seronegative and CMV-seropositive individuals were comparable [median SFC (range) of 0.7 (0.5-8.6) and 0.7 (0.5-2.5)/200,000 PBMC, respectively; Fig. 8]. Spot counts in IE-1- and pp65-stimulated PBMC of CMV-seronegative subjects were low [median SFC
Table 1 Technical validation cohort of healthy donors

\begin{tabular}{lc}
\hline Median age (range) in years & $33(21 ; 64)$ \\
Gender, N (\%) & $11(24.4 \%)$ \\
Male & $34(75.6 \%)$ \\
Female & \\
CMV serostatus, N (\%) & $32(71.1 \%)$ \\
Positive & $13(28.9 \%)$ \\
Negative & \\
\hline
\end{tabular}

(range) of 4.0 (2.0-52) and 1.4 (0.6-7.6)/200,000 PBMC, respectively; Fig. 8]. In $\mathrm{CMV}$-seropositive individuals, SFC levels in IE-1- and pp65-stimulated PBMC reached 1114 and 954 spot counts/200,000 PBMC (median of 22 and 265 respectively; Fig. 8). For the determination of a technical cut-off, spot counts in the unstimulated control as well as in T-activated ${ }^{\ominus}$ pp65- and IE-1stimulated conditions of CMV-seronegative and CMVseropositive individuals were taken into consideration. Positivity threshold was determined using z-statistics $(\alpha$-level $=0.05)$ on $\log 10$-transformed geometric mean

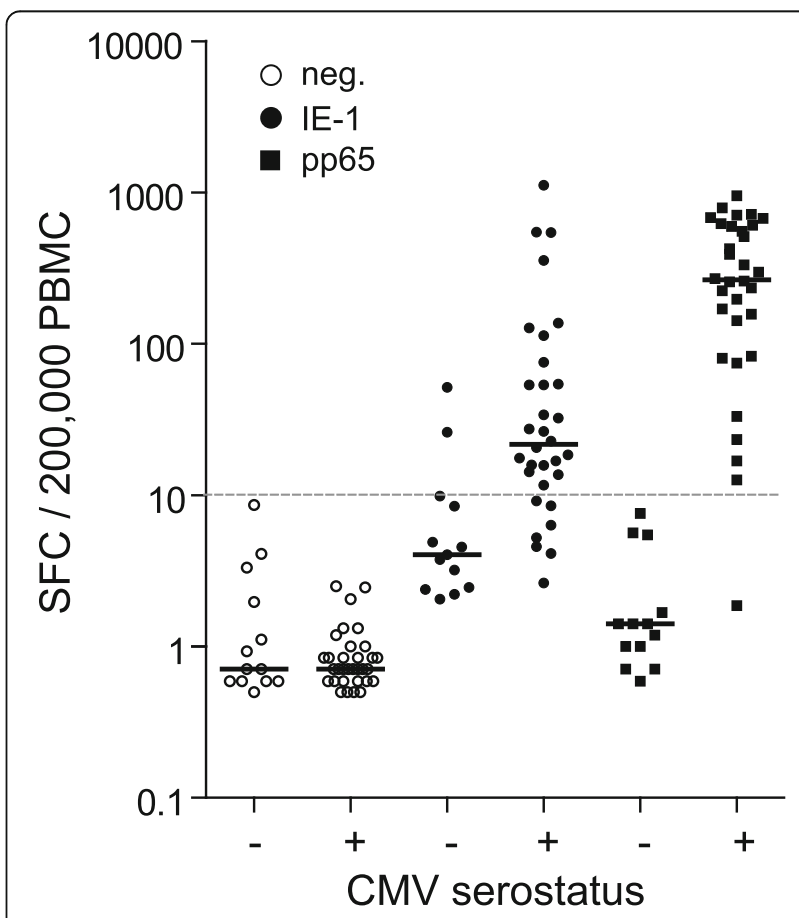

Fig. 8 Assay validation in immunocompetent donors. PBMC isolated from whole blood of 45 healthy donors (Table 1) were assayed using the optimized IFN- $\gamma$ ELISpot. A positivity cut-off of 10 SFC/200,000 PBMC (grey horizontal dashed line) was defined (see text and Additional File 2). Considering a test result as positive when the geometric mean for at least one of the IE-1 or pp65 stimulated approach is $\geq 10$ SFC/200,000 PBMC and when the ratio of geometric means of stimulated to unstimulated conditions is $\geq 2.5$, positive agreement (sensitivity) and negative agreement (specificity) of the optimized IFN- $\gamma$ ELISpot test results with CMV serology within this collective of healthy donors was $97 \%$ and $85 \%$ respectively 
values. Values $=0$ were replaced by values near detection limit, which was assumed to be 0.5. Standard deviation (SD) of ELISpot measurements for the unstimulated control, IE-1 stimulation and pp65 stimulation was respectively $0.234,0.192$ and 0.136 . Considering a SD of 0.2 and assuming that 4 replicates are measured for each negative control and test samples, a criterion that the ratio of geometric means of stimulated to unstimulated values is at least 2.5 was calculated. On the other hand, precision profiles were generated from both IE-1- and pp65-specific test results, whereby a coefficient of variation $(\mathrm{CV})$ no higher than $40 \%$ was used as a limit of acceptance of assay validity to determine the respective limit of quantitation (LoQ). Precision profiles for IE-1- and pp65-specific ELISpot results from the 45 healthy donors yielded LoQ values of 8.6 and 7.1 respectively (Additional File 2). Of note, a similar analysis performed on a cohort of 124 hemodialysis patients provided comparable $\mathrm{SD}$ values within unstimulated and antigen-stimulated conditions (range 0.199-0.240) and yielded LoQ values of 7.8 (IE-1) and 8.3 (pp65) [49]. Based on these analyses, a cut-off of 10 SFC/200,000 PBMC was chosen to define positive test results.

Altogether, using T-activated $^{\circ}$ pp65 and IE-1 antigens and the optimized IFN- $\gamma$ ELISpot assay, test results are considered positive if the geometric mean of the spots resulting from pp65 or IE1 stimulations are $\geq 10 \mathrm{SFC} /$ 200,000 PBMC and if the ratio of the geometric means of stimulated to non-stimulated conditions is $\geq 2.5$. According to these definitions, the collective of 45 healthy donors (32 CMV IgG-seropositive, 13 CMV IgG-seronegative) revealed a sensitivity (defined as the positive agreement with CMV IgG-serology, used as primary reference measurement procedure) of $97 \%$ and a specificity (negative agreement with CMV IgG-serology) of $85 \%$ (Fig. 8 ).

\section{Functional assay validation: T-activated antigens stimulate a broad spectrum of clinically relevant CMV-reactive effector cells}

Urea-formulated recombinant $\left(\mathrm{T}\right.$-activated $\left.{ }^{\circ}\right)$ proteins are processed by both the exogenous (MHC class II) and endogenous (MHC class I) antigen processing and presentation pathways [31]. Stimulation of PBMC by $\mathrm{T}$-activated ${ }^{\circ}$ proteins thus reproduces more closely a natural infection, potentially resulting in the activation of a broad spectrum of clinically relevant CMV-reactive cells (e.g., Th, CTL, NK, NKT cells; [5-12]), which might contribute to the high sensitivity of the IFN- $\gamma$ ELISpot assay. To further characterize the cells targeted by T-activated $^{\circ}$ IE-1 and pp65 antigens and to investigate the possible inter-individual variability in the effector cells response, intracellular IFN- $\gamma$ staining and flow cytometry analyses were performed in parallel to IFN- $\gamma$ ELISpot assays. Freshly isolated PBMC from six CMVseropositive healthy donors were stimulated with T-activated $^{\circ}$ IE-1 and pp65 proteins for $19 \mathrm{~h}$ and IFN- $\gamma$ producing cells enumerated according to the optimized ELISpot assay. The same PBMC preparations (4 replicates each) were stimulated for $6 \mathrm{~h}$ with the same batch of T-activated ${ }^{\circ}$ IE- 1 and pp65 proteins in the presence of co-stimulatory anti-CD28 and anti-CD49d antibodies. Surface markers (CD3, CD4, CD8, CD56) and intracellular IFN- $\gamma$ staining were analysed by flow cytometry, as described in the Methods section. IFN $-\gamma^{+}$subpopulations of $\mathrm{CD}^{+} \mathrm{CD}^{+}$(Th), $\mathrm{CD}^{+} \mathrm{CD}^{+}(\mathrm{CTL}), \mathrm{CD}^{+} \mathrm{CD}^{+} 6^{+}$ (NKT-like) and $\mathrm{CD}^{-}{ }^{-} \mathrm{CD} 56^{+}$(NK) lymphocytes were enumerated following the gating strategy illustrated in Additional File 3. All six donors differed in their capacity to elicit an IE-1- and/or pp65-dependent response in the IFN- $\gamma$ ELISpot assay. The intensity of the response was also heterogeneous among the six donors, with values ranging from 7 to 1,054 SFC (IE-1 stimulation) and from 28 to 780 SFC (pp65 stimulation) per 200,000 PBMC (Fig. 9a). Similarly, individual donors differed in the frequency and ratio of the various cell subpopulations investigated by flow cytometry (Fig. 9b). Interestingly, healthy CMVseropositive individuals with lower spot counts (d120, d300, d343; Fig. 9a) also showed lower frequencies of IFN$\mathrm{\gamma}^{+}$lymphocytes by flow cytometry (Fig. 9b), highlighting the ability of the ELISpot assay to distinguish low from high responders. Activation of each lymphocyte subpopulation investigated was detected in some but not all donors. For instance, weak to strong $\mathrm{CD}^{+}{ }^{+} \mathrm{T}$ cell activation was detected in 4 out of 6 donors (d120, d172, d300, d343) in response to either IE-1, pp65, or both. Similarly, 5 out of 6 donors (d172, d290, d300, d343, d361) showed $\mathrm{CD}^{+} \mathrm{T}$ cell activation in one or both stimulation conditions. CD3-CD56 ${ }^{+}$(NK cells) were apparent in one donor (d120) in response to both antigens. $\mathrm{CD}^{+} \mathrm{CD}^{+} 6^{+}$(NKTlike) cells were weakly activated in 4 out of 6 individuals (d120, d172 d300, d361) in response to both IE-1 and pp65 (Fig. 9b). Remarkably, a strong pp65-specific CD4 ${ }^{+}$ activation in d172 correlated with a strong pp65-specific response in ELISpot, and a strong pp65-specific (d290) and IE-1-specific (d361) $\mathrm{CD}^{+}$activation was associated with a high spot count in the corresponding ELISpot (Figs. 9a-b), suggesting that these CMV-reactive effector cells significantly contribute to the detected ELISpot signals. Altogether, these data demonstrate the ability of T-activated ${ }^{\oplus}$ IE-1 and pp65 proteins to stimulate a broad range of CMV-specific effector cells. These experiments also revealed the high heterogeneity of responses among healthy CMV-seropositive individuals. Notably, the observation that some individuals respond to either IE-1 or pp65 emphasizes the importance of assessing the response to both antigens. Monitoring both IE-1- and pp65-specific 


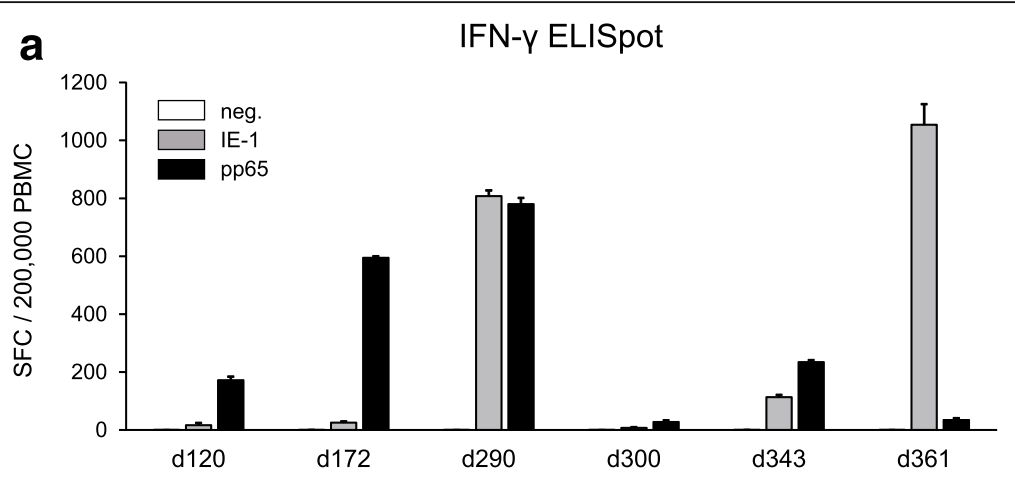

b $\quad$ Flow cytometry
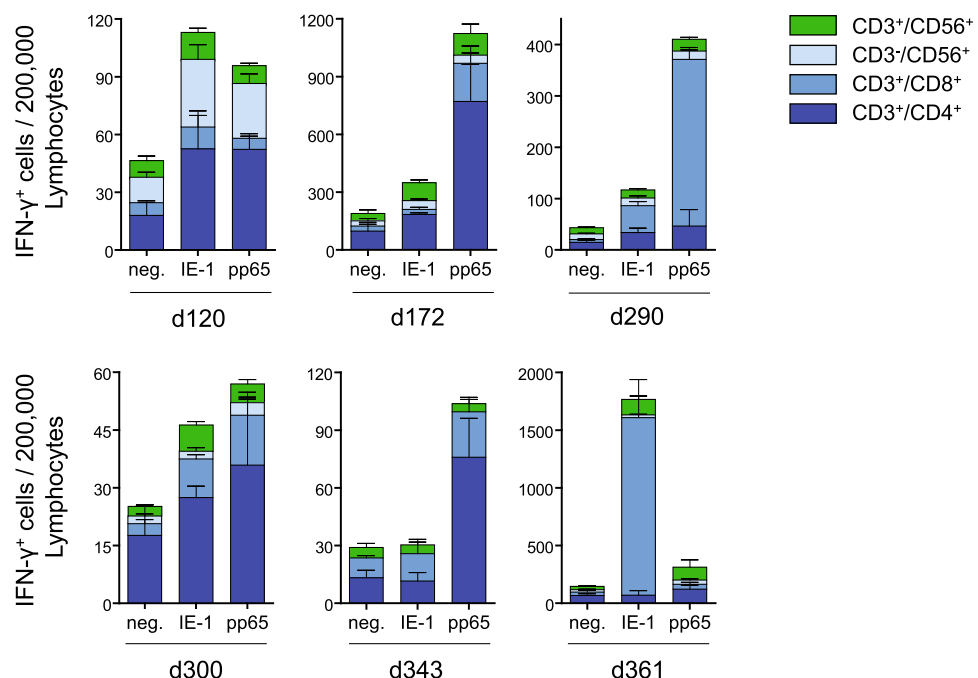

Fig. 9 T-activated ${ }^{\oplus}$ pp65 and IE-1 CMV antigens stimulate a broad range of CMV-reactive effector cells. Comparative analysis of IFN- $\gamma$ secreting cells by ELISpot (a) and flow cytometry (b) following stimulation of PBMC with T-activated ${ }^{\oplus}$ pp65 and IE-1 antigens. PBMC (4 replicates each) from six CMV-seropositive healthy donors (median age and range of 39 (22-55) years; 2 male and 4 female) were stimulated with T-activated ${ }^{\otimes}$ pp65 and IE-1 antigens according to the optimized IFN-y ELISpot (a) and to the protocol of intracellular and surface marker staining and flow cytometry described in the Methods section (b). Bar graphs in (a) depict IFN- $\gamma$-dependent SFC per 200,000 PBMC, as before. Bar graphs in (b) represent the number of IFN- $\gamma$-expressing $\mathrm{CD}^{+} \mathrm{CD}^{+}$(Th), $\mathrm{CD}^{+} \mathrm{CD}^{+}$(CTL), $\mathrm{CD}^{-} \mathrm{CD}^{+} 6^{+}$(NK) and $\mathrm{CD}^{+} \mathrm{CD}^{+} 6^{+}$(NKT-like) cells per 200,000 lymphocytes. Note that the $\mathrm{Y}$-axis scales in (b) were adjusted for a better resolution of the respective data. Individual age and gender of donors were as follows: d120, 37-year-old male; d172, 55-year-old female; d290, 46-year-old female; d300, 41-year-old female; d343, 24-year-old female; d361, 22-year-old male

responses in the optimized IFN- $\gamma$ ELISpot assay might improve the overall sensitivity of the test.

\section{Discussion}

We describe here the development and technical validation of an optimized and standardized IFN- $\gamma$ ELISpot protocol for the monitoring of CMV-reactive effector cells of cell-mediated immunity (CMI).

The particularity of the assay is the use of $\mathrm{T}$ activated $^{\bullet}$ proteins [31] as stimulant of CMV-reactive effector cells. We now demonstrate that ureaformulated IE-1 and pp65 proteins are capable of activating not only $\mathrm{CMV}$-reactive $\mathrm{CD}^{+}{ }^{+}(\mathrm{Th})$ and $\mathrm{CD} 8^{+}$ (CTL) lymphocytes, but also innate lymphocytes (CD3 ${ }^{-} \mathrm{CD}_{56}{ }^{+} \mathrm{NK}$ and $\mathrm{CD}^{+}{ }^{+} \mathrm{CD} 56^{+}$NKT-like cells), likely by bystander activation as well as by activation of CMV-specific memory NK cells $[5,7,8,32,50,51]$. This finding is important given the acknowledged role played by these effector cells in the protection against CMV reactivation in vivo [5-12]. Inter-individual variability in the response of lymphocyte subpopulations was high among CMV-seropositive healthy donors, therefore further emphasizing the importance of an antigen formulation capable of activating a broad spectrum of CMV-reactive effector cells. In this, the optimized IFN- $\gamma$ ELISpot assays outperforms existing ELISpot- and ELISA-based CMV-specific CMI monitoring tools. In addition, the characteristics and high sensitivity of our assay predict a performance independent of the HLA-type of the donor. 
The second particularity of the described assay is the combined use of two T-activated $^{\circledR}$ proteins, IE-1 and pp65, as antigens. We show here that both antigens can elicit the activation of distinct CMV-specific effector cells and that while some CMV-seropositive healthy individuals are reactive to both antigens, some are only reactive to one (either IE-1 or pp65), as previously reported [52]. Therefore, consideration of both test results is expected to improve the sensitivity of the assay, notably in cohort studies. This is particularly relevant for the monitoring of CMV-specific CMI in immunocompromized patients. Accordingly, we recently demonstrated the benefit of measuring the response to both T-activated $^{\oplus}$ IE-1 and pp65 antigens in terms of assay sensitivity, in clinical studies assessing CMV-specific CMI during pregnancy [53], in hemodialysis patients [49] and in renal transplant recipients (submitted).

The assessment of the response to both IE- 1 and pp65 antigens is further justified by the respective relevance and differential contribution of IE-1- and pp65-reactive effector cells to the protection against CMV reactivation and related clinical complications, both in healthy CMV-seropositive individuals and in transplant recipients $[1,6,54-59]$. The differential contribution of IE-1and pp65-specific effector cells likely reflect the dynamic of the cell-mediated immune response [10, 60-64]. Mechanisms of immune evasion inhibiting MHC-Idependent IE-1 antigen processing and presentation might also explain the lower frequency of IE-1-specific IFN- $\gamma$-producing cells detected in our ELISpot assay [65]. In addition, reduced processing and presentation efficiency due to protein stability, size and nuclear localization might play a role in the reduced reactivity to IE-1, as opposed to pp65 [64, 66, 67]. This proposition is supported by the observation that higher concentrations of IE-1 were required in our ELISpot assay, in comparison to pp65, to trigger a significant response.

Another particularity of our IFN- $\gamma$ ELISpot assay was its ability to elicit positive test results in CMVseronegative individuals, notably following stimulation with IE-1. In the cohort of 45 healthy donors, out of the 13 CMV-seronegative individuals 2 showed IE-1-specific values $\geq 10$ SFC/200,000 PBMC (Additional File 2), corresponding to a negative agreement with CMV IgGserology of $85 \%$. Similar results were obtained in a cohort of 124 hemodialysis patients [49]. Numerous studies reported discordant results between cellular and humoral immunity against CMV [68-71]. Given the high sensitivity of our ELISpot assay and its ability to detect a broad range of CMV-reactive cells, it is possible that cellular reactivity in CMV-seronegative individuals reflects a previous exposure to CMV that failed to mount a humoral immune response, rather than a false-positive ELISpot result. Further experiments will be necessary to address this possibility. Nonetheless, this observation raises the question of the accuracy of CMV serology to identify immunocompromised patients at increased risk of CMV reactivation [3, 70, 72].

The optimized and standardized IFN- $\gamma$ ELISpot assay exhibited robust performance in terms of assay variability, precision and linearity. Intra-assay, inter-assay and inter-operator coefficients of variations $(\mathrm{CV})$ did not exceed $22 \%$, which is below the range of recommended precision (\% of relative standard deviation or \%RSD) for cell-based assays [73]. As predicted, inter-site variability involving different operators was higher, but remained acceptable with a CV of no more than $39 \%$. This is an important criterion for the reliable longitudinal monitoring of CMV-specific immune responses in patients. Linearity of the assay is also a critical parameter, in particular for the monitoring of immunocompromized patients with reduced and/or functionally impaired $\mathrm{T}$ cells, such as children or recipients of allogeneic stem cell transplantation. Good linearity and high signal-to-noise ratio were obtained for both IE-1 $\left(R^{2}=0.97\right)$ and pp65 $\left(R^{2}=0.99\right)$ in the range of 60,000 to 200,000 PBMC per well. Two multi-center clinical studies are currently being conducted, in renal transplant recipients under immunosuppressive therapy and in allogeneic stem cell transplantation patients, to assess the sensitivity of the optimized CMV-specific IFN- $\gamma$ ELISpot assay in this clinical context and to correlate results of the assay to clinical outcome.

\section{Conclusions}

Altogether, this optimized, standardized and userfriendly CMV-specific IFN- $\gamma$ ELISpot assay meet all the conditions of a sensitive and reliable diagnostic test for the monitoring of the functionality of CMV-specific CMI. Beside its validation in healthy individuals (this study), its suitability to assess CMV-specific cellmediated immunity in a cohort of hemodialysis patients representative of patients prior to transplantation has been demonstrated [49]. Further validation of the assay in immunocompromised patients, such as transplant recipients is necessary to determine its suitability in assisting clinicians to evaluate the risk of CMV reactivation and disease, and possibly individualize the therapeutic management of patients.

\section{Abbreviations}

CMI: Cell-mediated immunity; CMV: Cytomegalovirus; CTL: Cytotoxic T lymphocyte; CV: Coefficient of variation; ELISA: Enzyme-linked immunosorbent assay; ELISpot: Enzyme-linked immunospot; HLA: Human leukocyte antigen;

ICS: Intracellular cytokine staining; IE-1: Immediate early-1 protein; IFN-y: Interferon gamma; LoQ: Limit of quantitation; NK: Natural killer cell; NKT: Natural killer T cell; PBMC: Peripheral blood mononuclear cell; pp65: 65 kDa lower matrix phosphoprotein; RSD: Relative standard deviation; SD: Standard deviation; SFC: Spot-forming cell; Th: T helper cell 


\section{Acknowledgements}

We thank Christina Paulus and Michael Nevels (University of Regensburg) for their support in IE-1 production and purification, and Thomas Keller (ACOMED Statistik) for statistical evaluation.

\section{Funding}

This project was funded by the Bayerische Forschungsstiftung Grants AZ 924-10 and AZ 1070-13 (ForBiMed project D5). The funding body had no role in the design of the study and in collection, analysis and interpretation of data and in writing the manuscript.

\section{Availability of data and materials}

The datasets supporting the conclusions of this article are included within the article and its additional files.

\section{Authors' contributions \\ SB and LD designed and supervised assay development. TS, CT, TL and SB performed experiments for assay development and analysed data. BA, RW and RK designed and supervised the flow cytometry experiment. RK performed the intracellular cytokine staining and flow cytometry experiment, and analysed data. AR, JB and HB drafted the manuscript and figures. All authors edited, read and/or approved the final version.}

\section{Competing interests}

$\mathrm{SB}, J \mathrm{~B}, \mathrm{HB}, \mathrm{LD}, \mathrm{AR}, \mathrm{TS}, \mathrm{CT}$ and $\mathrm{TL}$ are or were employees of Lophius Biosciences GmbH. LD is co-founder and Chief Scientific Officer of Lophius Biosciences $\mathrm{GmbH}$. RW is Chairman of the Board of Lophius Biosciences $\mathrm{GmbH}$. RW, SB and LD are shareholders of Lophius Biosciences $\mathrm{GmbH}$.

\section{Consent for publication}

Not applicable.

\section{Ethics approval and consent to participate}

Blood donation of healthy human volunteers was approved by the ethics committee of the University of Regensburg (approval number 11-122-0205)

All participants gave written informed consent before donations.

Received: 9 August 2016 Accepted: 10 February 2017

Published online: 07 March 2017

\section{Additional files}

Additional File 1: Assay variability. Intra-assay (Table S1.), inter-assay (Table S2.), inter-operator (Table S3.) and inter-site (Table S4.) variability was assessed as described in the respective legends. (PDF $128 \mathrm{~kb}$ )Additional File 2: Positivity cut-off definition. Results obtained using the optimized IFN- $\gamma$ ELISpot assay on PBMC isolated from whole blood of 45 healthy donors (Table 1 and Fig. 8) were used to generate precision profiles for each IE-1 and pp65 stimulation. Limits of quantitation (LoQ) for IE-1 and pp65 were 8.6 and 7.1 SFC/ 200,000 PBMC respectively. LoQ calculated on a cohort of 124 hemodialysis patients [49] were in a similar range (7.8 and 8.3 for IE-1 and pp65 respectively). Therefore, a positivity cut-off of $10 \mathrm{SFC} / 200,000 \mathrm{PBMC}$ was chosen for the standardized assay. In addition, intra-assay standard deviation (SD) within both cohorts of healthy donors ( $\mathrm{n}=$ $45)$ and hemodialysis patients $(n=124)$ for stimulated and unstimulated measurements was the basis for the calculation of a criterion that the ratio of geometric means of stimulated to unstimulated values is at least 2.5. Finally, considering a test result as positive when geometric mean for at least one of the IE- 1 or pp65 stimulated approach is $\geq$
10 SFC/200,000 PBMC, positive agreement (sensitivity) and negative agreement (specificity) of the optimized IFN- $\gamma$ ELISpot test results with CMV serology within the collective of 45 healthy donors was $97 \%$ and $85 \%$ respectively (Fig. 8). (PDF 73 kb)Additional File 3: Gating strategy of flow cytometry analyses following surface marker (CD3, CD4, CD8, CD56) and intracellular IFN- $\gamma$ staining. PBMC (4 replicates each) from six CMV-seropositive healthy donors were stimulated with T-activated $^{\oplus}$ pp65 and IE-1 antigens for $6 \mathrm{~h}$, as indicated in the legend to Fig. 9. (A) Cells were first gated on single events in a Forward Scatter-Area (FSC-A) x FSC-Height (FSC-H) dot plot (Gating \#1). Based on FSC-A x Side Scatter-Area (SSC-A) properties, a gate was next set around lymphocytes (Gating \#2). By plotting CD3 against CD56, CD56 single positive cells (Gating \#3), CD3/CD56 double positive cells (Gating \#4) and CD3 single positive cells (Gating \#5) were separated. CD3 single positive cells (Gating \#5) were further subdivided into $\mathrm{CD} 3 / \mathrm{CD} 4$ double positive (Gating \#6) and CD3/CD8 double positive cells (Gating \#7). (B) Representative dot plots (1 out of 4 replicates) of stained PBMC of donor d290. In each plot, percentage value in gated area is the mean frequency (from 4 replicates) of IFN- $\gamma$-expressing CD3 ${ }^{+} \mathrm{CD}^{+}$(Th), $\mathrm{CD}^{+} \mathrm{CD}^{+}$(CTL), $\mathrm{CD}^{-} \mathrm{CD}^{+} 6^{+}$(NK) and $\mathrm{CD}^{+} \mathrm{CD}^{+} 6^{+}$(NKT-like) cells. (PDF $351 \mathrm{~kb}$ )

References

1. Crough T, Khanna R. Immunobiology of human cytomegalovirus: from bench to bedside. Clin Microbiol Rev. 2009;22:76-98.

2. Fisher RA. Cytomegalovirus infection and disease in the new era of immunosuppression following solid organ transplantation. Transpl Infect Dis Off J Transplant Soc. 2009;11:195-202.

3. Kotton CN, Kumar D, Caliendo AM, Asberg A, Chou S, Danziger-Isakov L, et al. Updated international consensus guidelines on the management of cytomegalovirus in solid-organ transplantation. Transplantation. 2013;96:333-60.

4. Lisboa LF, Kumar D, Wilson LE, Humar A. Clinical utility of cytomegalovirus cell-mediated immunity in transplant recipients with cytomegalovirus viremia. Transplantation. 2012;93:195-200.

5. van Dommelen SLH, Tabarias HA, Smyth MJ, Degli-Esposti MA. Activation of natural killer (NK) T cells during murine cytomegalovirus infection enhances the antiviral response mediated by NK cells. J Virol. 2003;77:1877-84.

6. Sylwester AW, Mitchell BL, Edgar JB, Taormina C, Pelte C, Ruchti F, et al. Broadly targeted human cytomegalovirus-specific CD4+ and CD8+ T cells dominate the memory compartments of exposed subjects. J Exp Med. 2005;202:673-85.

7. Kamath AT, Sheasby CE, Tough DF. Dendritic cells and NK cells stimulate bystander T cell activation in response to TLR agonists through secretion of IFN-alpha beta and IFN-gamma. J Immunol. 2005:174:767-76.

8. Min-Oo G, Lanier LL. Cytomegalovirus generates long-lived antigen-specific NK cells with diminished bystander activation to heterologous infection. J Exp Med. 2014;211:2669-80.

9. Sester M, Sester U, Gärtner B, Heine G, Girndt M, Mueller-Lantzsch N, et al. Levels of virus-specific CD4 T cells correlate with cytomegalovirus control and predict virus-induced disease after renal transplantation. Transplantation. 2001;71:1287-94.

10. Sester M, Sester U, Gärtner BC, Girndt M, Meyerhans A, Köhler H. Dominance of virus-specific CD8 T cells in human primary cytomegalovirus infection. J Am Soc Nephrol JASN. 2002;13:2577-84.

11. Gamadia LE, Remmerswaal EBM, Weel JF, Bemelman F, van Lier RAW, Ten Berge IJM. Primary immune responses to human CMV: a critical role for IFN- 
gamma-producing CD4+ T cells in protection against CMV disease. Blood. 2003;101:2686-92.

12. Hanley PJ, Bollard CM. Controlling cytomegalovirus: helping the immune system take the lead. Viruses. 2014;6:2242-58.

13. Walker S, Fazou C, Crough T, Holdsworth R, Kiely P, Veale M, et al. Ex vivo monitoring of human cytomegalovirus-specific CD8+ T-cell responses using QuantiFERON-CMV. Transpl Infect Dis Off J Transplant Soc. 2007;9:165-70.

14. Lehmann PV, Zhang W. Unique strengths of ELISPOT for T cell diagnostics. Methods Mol Biol Clifton NJ. 2012;792:3-23.

15. Tassignon J, Burny W, Dahmani S, Zhou L, Stordeur P, Byl B, et al. Monitoring of cellular responses after vaccination against tetanus toxoid: comparison of the measurement of IFN-gamma production by ELISA, ELISPOT, flow cytometry and real-time PCR. J Immunol Methods. 2005;305:188-98.

16. Abate D, Saldan A, Mengoli C, Fiscon M, Silvestre C, Fallico L, et al. Comparison of cytomegalovirus (CMV) enzyme-linked immunosorbent spot and CMV quantiferon gamma interferon-releasing assays in assessing risk of CMV infection in kidney transplant recipients. J Clin Microbiol. 2013;51:2501-7.

17. Abate D, Saldan A, Forner G, Tinto D, Bianchin A, Palù G. Optimization of interferon gamma ELISPOT assay to detect human cytomegalovirus specific T-cell responses in solid organ transplants. J Virol Methods. 2014;196:157-62.

18. Abate D, Cesaro S, Cofano S, Fiscon M, Saldan A, Varotto S, et al. Diagnostic utility of human cytomegalovirus-specific T-cell response monitoring in predicting viremia in pediatric allogeneic stem-cell transplant patients. Transplantation. 2012;93:536-42.

19. Manuel O, Husain S, Kumar D, Zayas C, Mawhorter S, Levi ME, et al. Assessment of cytomegalovirus-specific cell-mediated immunity for the prediction of cytomegalovirus disease in high-risk solid-organ transplant recipients: a multicenter cohort study. Clin Infect Dis Off Publ Infect Dis Soc Am. 2013;56:817-24.

20. Clari MÁ, Muñoz-Cobo B, Solano C, Benet I, Costa E, Remigia MJ, et al. Performance of the QuantiFERON-cytomegalovirus (CMV) assay for detection and estimation of the magnitude and functionality of the CMVspecific gamma interferon-producing CD8(+) T-cell response in allogeneic stem cell transplant recipients. Clin Vaccine Immunol CVI. 2012;19:791-6.

21. Fleming T, Dunne J, Crowley B. Ex vivo monitoring of human cytomegalovirus-specific CD8(+) T-Cell responses using the QuantiFERONCMV assay in allogeneic hematopoietic stem cell transplant recipients attending an Irish hospital. J Med Virol. 2010;82:433-40.

22. Cox JH, Ferrari G, Janetzki S. Measurement of cytokine release at the single cell level using the ELISPOT assay. Methods San Diego Calif. 2006;38:274-82.

23. Karlsson AC, Martin JN, Younger SR, Bredt BM, Epling L, Ronquillo R, et al. Comparison of the ELISPOT and cytokine flow cytometry assays for the enumeration of antigen-specific T cells. J Immunol Methods. 2003;283:141-53.

24. Tischer S, Dieks D, Sukdolak C, Bunse C, Figueiredo C, Immenschuh S, et al. Evaluation of suitable target antigens and immunoassays for high-accuracy immune monitoring of cytomegalovirus and Epstein-Barr virus-specific T cells as targets of interest in immunotherapeutic approaches. J Immunol Methods. 2014;408:101-13.

25. Meierhoff G, Ott PA, Lehmann PV, Schloot NC. Cytokine detection by ELISPOT: relevance for immunological studies in type 1 diabetes. Diabetes Metab Res Rev. 2002;18:367-80.

26. Forner G, Saldan A, Mengoli C, Gussetti N, Palù G, Abate D. CMV-ELISPOT but not CMV-QuantiFERON assay is a novel biomarker to determine the risk of congenital CMV infection in pregnant women. J Clin Microbiol. 2016;54:2149-54.

27. Saldan A, Forner G, Mengoli C, Tinto D, Fallico L, Peracchi M, et al. Comparison of the Cytomegalovirus (CMV) Enzyme-Linked Immunosorbent Spot and CMV QuantiFERON Cell-Mediated Immune Assays in CMV-Seropositive and -Seronegative Pregnant and Nonpregnant Women. J Clin Microbiol. 2016;54:1352-6.

28. Saldan A, Forner G, Mengoli C, Gussetti N, Palù G, Abate D. Strong cellmediated immune response to human cytomegalovirus is associated with increased risk of fetal infection in primarily infected pregnant women. Clin Infect Dis Off Publ Infect Dis Soc Am. 2015;61:1228-34.

29. Godard B, Gazagne A, Gey A, Baptiste M, Vingert B, Pegaz-Fiornet B, et al. Optimization of an elispot assay to detect cytomegalovirus-specific CD8+ T lymphocytes. Hum Immunol. 2004;65:1307-18.

30. Schmittel A, Keilholz U, Scheibenbogen C. Evaluation of the interferongamma ELISPOT-assay for quantification of peptide specific T lymphocytes from peripheral blood. J Immunol Methods. 1997;210:167-74.

31. Barabas S, Gary R, Bauer T, Lindner J, Lindner P, Weinberger B, et al. Ureamediated cross-presentation of soluble Epstein-Barr virus BZLF1 protein. PLoS Pathog. 2008;4:e1000198.
32. Cerwenka A, Lanier LL. Natural killer cell memory in infection, inflammation and cancer. Nat Rev Immunol. 2016;16:112-23.

33. Rowe WP, Hartley JW, Waterman S, Turner HC, Huebner RJ. Cytopathogenic agent resembling human salivary gland virus recovered from tissue cultures of human adenoids. Proc Soc Exp Biol Med Soc Exp Biol Med N Y N. 1956; 92:418-24.

34. McKenna KC, Beatty KM, Vicetti Miguel R, Bilonick RA. Delayed processing of blood increases the frequency of activated CD11b + CD15+ granulocytes which inhibit T cell function. J Immunol Methods. 2009;341:68-75.

35. Xu J, Wu R, Xiang F, Kong Q, Hong J, Kang X. Diversified phenotype of antigen specific CD8+ $T$ cells responding to the immunodominant epitopes of IE and pp 65 antigens of human cytomegalovirus. Cell Immunol. 2015; 295:105-11.

36. Hesse MD, Karulin AY, Boehm BO, Lehmann PV, Tary-Lehmann M. A T cell clone's avidity is a function of its activation state. J Immunol. 2001;167: 1353-61.

37. Elkington R, Walker $\mathrm{S}$, Crough T, Menzies M, Tellam J, Bharadwaj M, et al. Ex vivo profiling of CD8 +-T-cell responses to human cytomegalovirus reveals broad and multispecific reactivities in healthy virus carriers. J Virol. 2003;77:5226-40.

38. Avetisyan $G$, Aschan J, Hägglund H, Ringdén O, Ljungman P. Evaluation of intervention strategy based on CMV-specific immune responses after allogeneic SCT. Bone Marrow Transplant. 2007;40:865-9.

39. Mattes FM, Vargas A, Kopycinski J, Hainsworth EG, Sweny P, Nebbia G, et al. Functional impairment of cytomegalovirus specific CD8 T cells predicts high-level replication after renal transplantation. Am J Transplant Off J Am Soc Transplant Am Soc Transpl Surg. 2008;8:990-9.

40. Costa C, Balloco C, Sidoti F, Mantovani S, Rittà M, Piceghello A, et al. Evaluation of CMV-specific cellular immune response by EliSPOT assay in kidney transplant patients. J Clin Virol Off Publ Pan Am Soc Clin Virol. 2014; 61:523-8.

41. Costa C, Astegiano S, Terlizzi ME, Sidoti F, Curtoni A, Solidoro P, et al. Evaluation and significance of cytomegalovirus-specific cellular immune response in lung transplant recipients. Transplant Proc. 2011:43:1159-61.

42. Bestard O, Lucia M, Crespo E, Van Liempt B, Palacio D, Melilli E, et al. Pretransplant immediately early-1-specific $T$ cell responses provide protection for CMV infection after kidney transplantation. Am J Transplant Off J Am Soc Transplant Am Soc Transpl Surg. 2013;13:1793-805.

43. Smith SG, Joosten SA, Verscheure V, Pathan AA, McShane H, Ottenhoff THM, et al. Identification of major factors influencing ELISpot-based monitoring of cellular responses to antigens from Mycobacterium tuberculosis. PLoS One. 2009;4:e7972.

44. Moodie Z, Price L, Janetzki S, Britten CM. Response determination criteria for ELISPOT: toward a standard that can be applied across laboratories. Methods Mol Biol Clifton NJ. 2012;792:185-96.

45. Moodie Z, Price L, Gouttefangeas C, Mander A, Janetzki S, Löwer M, et al. Response definition criteria for ELISPOT assays revisited. Cancer Immunol Immunother CII. 2010;59:1489-501.

46. Dittrich M, Lehmann PV. Statistical analysis of ELISPOT assays. Methods Mol Biol Clifton NJ. 2012;792:173-83.

47. Krakauer T. Immune response to staphylococcal superantigens. Immunol Res. 1999;20:163-73.

48. Hao XS, Le JM, Vilcek J, Chang TW. Determination of human T cell activity in response to allogeneic cells and mitogens. An immunochemical assay for gamma-interferon is more sensitive and specific than a proliferation assay. J Immunol Methods. 1986;92:59-63.

49. Banas B, Böger CA, Lückhoff G, Krüger B, Barabas S, Batzilla J, Schemmerer M, Köstler J, Bendfeldt H, Rascle A, Wagner R, Deml L, Leicht J, Krämer BK. Validation of T-Track ${ }^{\oplus} \mathrm{CMV}$ to assess the functionality of cytomegalovirusreactive cell-mediated immunity in hemodialysis patients. BMC Immunology. 2017. doi:10.1186/s12865-017-0194-z.

50. Reschner A, Hubert P, Delvenne P, Boniver J, Jacobs N. Innate lymphocyte and dendritic cell cross-talk: a key factor in the regulation of the immune response. Clin Exp Immunol. 2008;152:219-26.

51. Ferlazzo G, Morandi B. Cross-talks between natural killer cells and distinct subsets of dendritic cells. Front Immunol. 2014;5:159.

52. Kern F, Surel IP, Faulhaber N, Frömmel C, Schneider-Mergener J, Schönemann C, et al. Target structures of the CD8(+)-T-cell response to human cytomegalovirus: the 72-kDa major immediate-early protein revisited. J Virol. 1999;73:8179-84.

53. Reuschel E, Barabas S, Zeman F, Bendfeldt H, Rascle A, Deml L, et al. Functional impairment of CMV-reactive cellular immunity during pregnancy. J Med Virol. 2017;89:324-31. 
54. Nickel P, Bold G, Presber F, Biti D, Babel N, Kreutzer S, et al. High levels of CMV-IE-1-specific memory $T$ cells are associated with less alloimmunity and improved renal allograft function. Transpl Immunol. 2009;20:238-42.

55. Egli A, Binet I, Binggeli S, Jäger C, Dumoulin A, Schaub S, et al. Cytomegalovirusspecific T-cell responses and viral replication in kidney transplant recipients. J Transl Med. 2008:6:29.

56. Bunde T, Kirchner A, Hoffmeister B, Habedank D, Hetzer R, Cherepnev $\mathrm{G}$, et al. Protection from cytomegalovirus after transplantation is correlated with immediate early 1-specific CD8 T cells. J Exp Med. 2005; 201:1031-6.

57. Tormo N, Solano C, Benet I, Nieto J, de la Cámara R, Garcia-Noblejas A, et al. Kinetics of cytomegalovirus (CMV) pp 65 and IE-1-specific IFNgamma CD8+ and CD4+ T cells during episodes of viral DNAemia in allogeneic stem cell transplant recipients: potential implications for the management of active CMV infection. J Med Virol. 2010;82:1208-15.

58. Meij P, Jedema I, Zandvliet ML, van der Heiden PL, van de Meent M, van

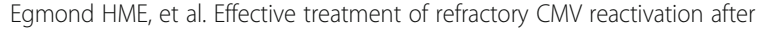
allogeneic stem cell transplantation with in vitro-generated CMV pp 65specific CD8+ T-cell lines. J Immunother. 2012;35:621-8.

59. Feuchtinger T, Opherk K, Bethge WA, Topp MS, Schuster FR, Weissinger EM, et al. Adoptive transfer of pp 65-specific T cells for the treatment of chemorefractory cytomegalovirus disease or reactivation after haploidentical and matched unrelated stem cell transplantation. Blood. 2010;116:4360-7.

60. Widmann T, Sester U, Gärtner BC, Schubert J, Pfreundschuh M, Köhler H, et al. Levels of CMV specific CD4 T cells are dynamic and correlate with CMV viremia after allogeneic stem cell transplantation. PLoS One. 2008;3:e3634.

61. Sacre K, Carcelain G, Cassoux N, Fillet A-M, Costagliola D, Vittecoq D, et al. Repertoire, diversity, and differentiation of specific CD8 T cells are associated with immune protection against human cytomegalovirus disease. J Exp Med. 2005;201:1999-2010.

62. Gerna G, Lilleri D, Fornara C, Comolli G, Lozza L, Campana C, et al. Monitoring of human cytomegalovirus-specific CD4 and CD8 T-cell immunity in patients receiving solid organ transplantation. Am J Transplant Off J Am Soc Transplant Am Soc Transpl Surg. 2006;6:2356-64.

63. Sester M, Sester U, Gärtner B, Kubuschok B, Girndt M, Meyerhans A, et al. Sustained high frequencies of specific CD4 T cells restricted to a single persistent virus. J Virol. 2002;76:3748-55.

64. Tabi Z, Moutaftsi M, Borysiewicz LK. Human cytomegalovirus pp 65- and immediate early 1 antigen-specific HLA class I-restricted cytotoxic T cell responses induced by cross-presentation of viral antigens. J Immunol. 2001;166:5695-703.

65. Gilbert MJ, Riddell SR, Li CR, Greenberg PD. Selective interference with class I major histocompatibility complex presentation of the major immediateearly protein following infection with human cytomegalovirus. J Virol. 1993;67:3461-9.

66. Scheller N, Furtwängler R, Sester U, Maier R, Breinig T, Meyerhans A. Human cytomegalovirus protein pp 65: an efficient protein carrier system into human dendritic cells. Gene Ther. 2008;15:318-25.

67. Delmas S, Martin L, Baron M, Nelson JA, Streblow DN, Davignon J-L. Optimization of CD4+ T lymphocyte response to human cytomegalovirus nuclear IE1 protein through modifications of both size and cellular localization. J Immunol. 2005;175: 6812-9.

68. Loeth N, Assing K, Madsen HO, Vindeløv L, Buus S, Stryhn A. Humoral and cellular CMV responses in healthy donors; identification of a frequent population of CMV-specific, CD4+ T cells in seronegative donors. PLoS One. 2012;7:e31420

69. Lúcia M, Crespo E, Melilli E, Cruzado JM, Luque S, Llaudó I, et al. Preformed frequencies of cytomegalovirus (CMV)-specific memory T and B cells identify protected CMV-sensitized individuals among seronegative kidney transplant recipients. Clin Infect Dis Off Publ Infect Dis Soc Am. 2014;59: 1537-45.

70. Sester M, Gärtner BC, Sester U, Girndt M, Mueller-Lantzsch N, Köhler H. Is the cytomegalovirus serologic status always accurate? A comparative analysis of humoral and cellular immunity. Transplantation. 2003;76:1229-30.

71. Zhu J, Shearer GM, Marincola FM, Norman JE, Rott D, Zou JP, et al. Discordant cellular and humoral immune responses to cytomegalovirus infection in healthy blood donors: existence of a Th1-type dominant response. Int Immunol. 2001;13: 785-90.
72. Schmidt T, Ritter M, Dirks J, Gärtner BC, Sester U, Sester M. Cytomegalovirusspecific T-cell immunity to assign the infection status in individuals with passive immunity: a proof of principle. J Clin Virol Off Publ Pan Am Soc Clin Virol. 2012;54:272-5.

73. Tuomela M, Stanescu I, Krohn K. Validation overview of bio-analytical methods. Gene Ther. 2005;12 Suppl 1:S131-138.

\section{Submit your next manuscript to BioMed Central and we will help you at every step:}

- We accept pre-submission inquiries

- Our selector tool helps you to find the most relevant journal

- We provide round the clock customer support

- Convenient online submission

- Thorough peer review

- Inclusion in PubMed and all major indexing services

- Maximum visibility for your research

Submit your manuscript at www.biomedcentral.com/submit
Biomed Central 